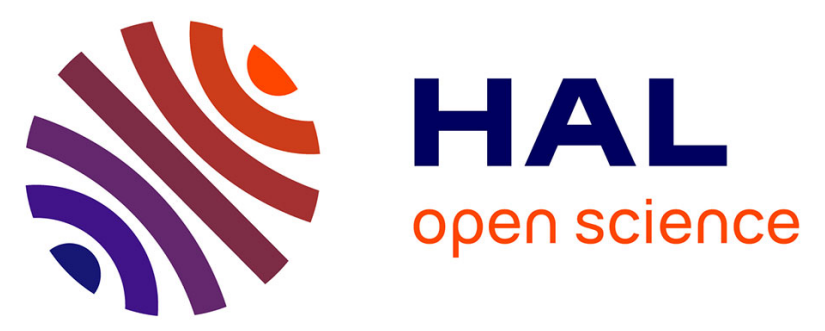

\title{
Identification of Sensitive Driving Situations to Guide the Design of a Learning Tool for Automated Vehicle Drivers
}

Hugo Cusanno, Christine Vidal-Gomel, Sophie Le Bellu

\section{To cite this version:}

Hugo Cusanno, Christine Vidal-Gomel, Sophie Le Bellu. Identification of Sensitive Driving Situations to Guide the Design of a Learning Tool for Automated Vehicle Drivers. Proceedings of the 21st Congress of the International Ergonomics Association (IEA 2021): Volume I: Systems and Macroergonomics. Springer Nature., pp.462-470, 2021, 10.1007/978-3-030-74602-5_65 . halshs-03287038

\section{HAL Id: halshs-03287038 \\ https://shs.hal.science/halshs-03287038}

Submitted on 15 Jul 2021

HAL is a multi-disciplinary open access archive for the deposit and dissemination of scientific research documents, whether they are published or not. The documents may come from teaching and research institutions in France or abroad, or from public or private research centers.
L'archive ouverte pluridisciplinaire HAL, est destinée au dépôt et à la diffusion de documents scientifiques de niveau recherche, publiés ou non, émanant des établissements d'enseignement et de recherche français ou étrangers, des laboratoires publics ou privés. 


\title{
Identification of sensitive driving situations to guide the design of a learning tool for automated vehicle drivers
}

\author{
Hugo Cusanno ${ }^{1-2}$, Christine Vidal-Gomel ${ }^{1}$ and Sophie Le Bellu ${ }^{2-3}$ \\ ${ }^{1}$ Université de Nantes, CREN EA2661, France \\ ${ }^{2}$ Renault SAS, France \\ ${ }^{2}$ Université de Bordeaux, ENSC, IMS Cognitique UMR5218, France \\ Hugo.cusanno@univ-nantes.fr
}

\begin{abstract}
This paper presents a research process aiming at studying the activity of drivers in automated vehicles (AV). To do this, we carried out in situ observations and conducted interviews with two different populations: professional and novice drivers in automated driving (AD). The results obtained by triangulation highlight a series of "sensitive" situations specific to automated driving. The clinical analysis of these situations shows changes in the relations and mediations involved. Some of them have common characteristics, making it possible to classify the sensitive situations identified. These changes require a potential adaptation of "traditional" driving schemes, necessary for the appropriation of the AV by the drivers. These results allow us to provide recommendations for improving AV prototypes, and to consider the design of a learning tool to support the appropriation of these systems. This device should, at a minimum, make it possible to familiarize vehicle drivers with sensitive driving situations, in order to initiate the transformation of their schemes upstream, and to cognitively relieve them in real driving situations.
\end{abstract}

Keywords: Automated driving, Sensitive driving situations, Instrumental Genesis, Learning tool design.

\section{Introduction}

Technological innovation progress in the automotive industry is leading manufacturers to offer more and more features in vehicles. It also brings new driving modes intended to either help, assist and even partially or completely replace the driver. These new driving modes have been categorized by the SAE into five levels (Society of Automotive Engineers, 2018). In this paper we will only focus on SAE Levels 3 and 4 . These levels offer a driving mode in which the role change between the driver and the system disrupts the driving activity from manual to highly automated, and vice versa (Kyriakidis et al., 2019). This change is not trivial and requires knowing it better in order to guide and support future automated vehicles (AV) drivers. Therefore, we set up a research process that allows us to engage a reflection on how to guide appropriation (instrumental genesis in the sense of Rabardel, 1995; Verillon \& Rabardel, 1995), first of the AV itself, but also of the learning tools we contribute 
to develop. We consider automated driving, just like "traditional" driving, to be an instrumented collective activity (Mundutéguy \& Darses, 2007; Vidal-Gomel et coll., 2014). It is from this angle, and with a situational approach, that we deployed a process to analyze professional (people working for the company whose job is to drive vehicles and prototypes under various conditions in order to test the maximum functionalities and limitations) and novice AV drivers' activity (Cusanno, Vidal-Gomel \& Le Bellu, 2019, 2020). We first conducted a study with professional drivers and then completed and compared it with a second study aimed at analyzing the activity of novice AV drivers. We seek to understand the transformations produced in the drivers' activity and possible difficulties during the instrumental genesis (op. cit.). This, in order to guide the design of future AVs and the design of learning tools to support their appropriation by drivers new to these systems.

\section{$2 \quad$ Methodology}

\subsection{Two populations studied; two methodologies deployed}

A collection of professional AV drivers' experience and knowledge. The first study allowed to follow nine professional AV drivers experts (in the sense of Lefèbvre, 2001), in a four-step research process: (1) exploratory semi-structured interviews, (2) instrumented observations on open roads in AV prototype, (3) individual auto-confrontation interviews, and (4) a collective allo-confrontation interview (Mollo \& Falzon, 2004). Details in Cusanno, Vidal-Gomel et Le Bellu (2020).

A study to understand AV novice drivers' difficulties. The second study is based on an experiment carried out as part of a European project aims to carry out experiments with automated levels 3 and 4 SAE vehicles. It takes place on various experimental sites or open roads in Europe, in order to assess the impact of automated vehicle deployment, on its acceptability, mobility, traffic, road safety, etc. We study more specifically the driving activity of twenty AV novice drivers. We follow their progress during three consecutive driving sessions of around $1 \mathrm{~h} 30$ each $(\mathrm{t} 0, \mathrm{t} 0+1$ month, $\mathrm{t} 0+4$ months) with an AV prototype on the highway. Two persons are systematically present in the vehicle. A safety driver (who followed specific training created by a driving school trainer to handle the dual command), seated in the right front passenger seat, is responsible for ensuring the safety of the experiments by taking back control of the vehicle in potentially risky driving situations. And a supervisor, seated in the right rear seat, oversees by checking that the system is operating correctly. An ergonomist is also present in the vehicle during driving sessions 1 and 3. He oversees the participants' pre-driving briefing, including a short indoor training session (30 minutes) and a test on track (45 minutes) to get started with the prototype. During the drive, participants are asked to verbalize their feelings aloud; the ergonomist is responsible for taking notes and verbal reminders. He then conducts auto-confrontation interviews with each participant, based on an interview guide created upstream. 


\subsection{Equipment used for open road experiments}

AV prototype. For both studies we used the same prototype which is an AV level 34 SAE draft. In addition to "traditional" manual driving, it offers an automated driving mode available on highway with at least two lanes. When AD is available, the driver must meet certain restrictive conditions inherent in the prototype to activate it. Once AD is activated, the vehicle manages all aspects of driving and the driver can theoretically have other occupations. The driver can take back control whenever he wants. The vehicle can also ask the driver to take over driving, in 60 seconds, if it arrives on a section of highway that is no longer suitable for AD. To achieve this, the driver has the choice between pressing the accelerator or brake pedal, or moving the steering wheel, or pressing a button on the steering wheel.

Instrumented data collection. In both experiments, the vehicle was equipped with audio-video data collection systems. We used two cameras, one facing the driving scene, close to the driver's point of view, and the other facing the driver himself. We recorded the driver's verbalizations while driving with a dictaphone and took notes. Audio-video recordings were also made during in-room interview sessions.

\subsection{Data processing}

Our goal is to identify characteristics of driving situations that are potentially difficult, risky, or requiring increased attention for AV novice drivers. We call them "sensitive situations". The qualitative data from the two studies were treated in the same way. All interviews audio recordings were transcribed, and the videos were analyzed chronologically, situation after situation. We then proceeded to thematic analyzes of the interviews, which we put in front of the corresponding video sequences and simultaneous verbalizations. The most recurring situations were analyzed in more detail from a clinical point of view (Clot \& Leplat, 2005) using the CIAS (Collective Instrumented Activity Situation) model of Rabardel (1995; Verillon \& Rabardel, 1995). This model makes it possible to identify the relations and mediations at stake in a situation between the subject ( $\mathrm{S}$; the driver), the instrument (I; the AV), the object of the activity ( $\mathrm{O}$; the driving), and other people ( $\mathrm{P}$; other drivers, passengers, etc.). Thus, we can approach the scheme transformations potentially required for a more effective management of these situations, from the point of view of professional and novice AV driver. Thanks to the triangulation (Apostolidis, 2003; Olsen, 2004) of data from the two studies, we sought to characterize what could be the instrumental genesis of future AV drivers.

\section{Results}

\subsection{A list of 32 « sensitive » driving situations specific to AD}

The study of AV professional drivers identified 27 sensitive situations. This list was confirmed and completed thanks to our second study in which we collected 25 sensitive situations, including 20 similar to the first study. This brings us to a total of 32 
sensitive situations. The clinical analysis of each of these situations allowed us to categorize them from the point of view of system operation and the experience of the participants:

- Cat. 1: Sensitive situations related to AD activation $(N=6)$. E.g. If the driver activates $\mathrm{AD}$ while being too close to the preceding vehicle, the system will brake to recover the safety distance, creating surprise and discomfort for the driver.

- Cat. 2: Sensitive situations related to nominal AD operation $(N=7)$. E.g. When the $\mathrm{AV}$ passes by an insertion lane, it does not anticipate the insertion of other vehicles as a human driver would.

- Cat. 3: Sensitive situations related to nominal AD operation but critical from the driver's point of view $(\mathrm{N}=6)$. E.g. When the AV passes a large truck, it does not shift in its lane like a human driver might do to keep a lateral safety distance.

- Cat. 4: Sensitive situations related to AD limits known by the system, leading to a quick take over request, only in $\mathrm{AD}$ Level $3 \mathrm{SAE}(\mathrm{N}=5)$. E.g. If the system detects a work area on the road, it will then ask the driver to take over the driving, giving him 10 seconds to act.

- Cat. 5: Sensitive situations related to AC limits not recognized by the system and critical from the driver's point of view $(\mathrm{N}=3)$. These situations require voluntary action by the driver, without assistance from the system; The driver must know how to recognize and anticipate these situations to take over the driving. E.g. If an emergency vehicle wants to pass, the AV is not able to locate it precisely and let it pass, so the driver must make the decision to act quickly.

- Cat. 6: Sensitive situations related to the deactivation of AD (take over the driving) $(\mathrm{N}=5)$. E.g. If the driver deactivates in a curve, he must keep the correct angle with the steering wheel to avoid swerving in the lane.

\subsection{Three classes of sensitive situations: mobilized relations and mediations}

Analysis of sensitive situations based on the CIAS model (op. cit.) allows us to identify common characteristics between some of our situation categories. We classify them this way: (A) activation and deactivation situations (cat. 1, 4 and 6), (B) driving situations managed by $\mathrm{AD}$ (cat. 2 and 3), and (C) the ambiguous situations of $\mathrm{AD}$ (cat. 5). In this section we use the graphical representation of the CIAS model emphasizing the relations (solid lines) and mediations (dotted lines) between entities. As a reminder: the subject (S; the driver), the instrument (I; the AV), the object of the activity ( $\mathrm{O}$; the driving), and other people (P; other drivers, passengers, etc.). We present below (cf. Fig. 1) an example of a class (A) CIAS model of a situation of deactivation in a curve (cat. 6) :

Fig. 1. CIAS Model: situation of deactivation in a curve (cat. 6)

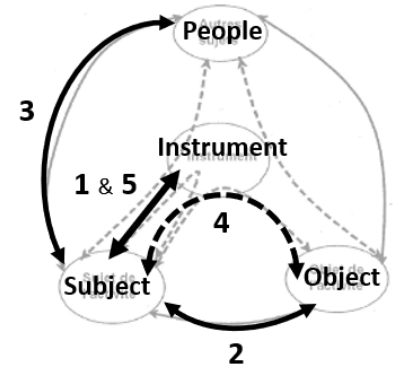

To deactivate $\mathrm{AD}$ and take over the drive (subject's goal), the subject must: (a) analyze and understand the messages coming from his vehicle (dashboard interface, sounds, etc.) indicating that he must take 
control (1: S-I relation) ; (b) understand the driving activity (speed, lane, angle of turn, etc.) of his vehicle (2: S-O relation); (c) become aware of the state of surrounding traffic and other vehicles behaviors (3: S-P relation); and (d) associate the possible actions according to the situational context, and be able to anticipate and decide on the action to deactivate (4: S-I-O mediation). Once AD is deactivated, the driver can check the intended result by looking the same interfaces (5: S-I relation).

In this class of situations, the main differences with "traditional" driving are understanding the new AV interfaces (1: S-I relation), and knowledge of activation and deactivation procedures depending on the context (4: S-I-O mediation).

For class (B), the main differences with "traditional" driving lie in the understanding of the AV driving behavior depending on the situations (I-O relation), and in the driver's ability to potentially inhibit some of his "traditional" driving automatisms in these situations (S-I-S reflective mediation). Class $(C)$ combines both the differences with "traditional" driving identified in class (A), and those identified in class (B). However, S-I-S mediation is not present since the AV does not indicate anything specific to the driver. This is due to the contrast between the AV behavior (I-O relation) and the context perceived by the subject (S-O and S-P relations).

\subsection{Two different populations, two ways to apprehend AD}

Our observations show that the management of the AV driving activity differs from one population to another. Professional drivers are more conscientious because they play the role of driver, safety driver and supervisor of the second study at the same time. They are therefore extremely focused on driving tasks, on traffic monitoring, but also and above all on monitoring the AV behavior. Also, traces of their professional activity remain visible, especially when they report that they usually take over the driving at the last moment in order to let the AV try to manage the situations and record as much data as possible that will be used to improve the prototype. Some of them told us they felt exhausted after just two hours of driving due to cognitive load this activity represents:

"After two hours we are exhausted. You are not driving but it's even worse, you have to expect the worst at any time, so you have your hands an inch from the wheel, your eyes are on the road really everywhere at the same time, and you can take over the drive at any time ». Study 1 , subject 1 .

Conversely, more than $60 \%$ of novice drivers delegate this responsibility to the safety driver, and are more trustful because he can manage problematic situations:

"We have a human safety driver; we tend to trust him. [...] This is a bias: we trust him, so we are not in supervision mode $»$. Study 2 , subject 8 .

Professional drivers are aware of and express changes in their management of certain situations, reflecting an adaptation of "traditional" driving schemes. This allowed us to gather advices and recommendations to better appropriate the $\mathrm{AV}(\mathrm{Cu}-$ sanno, Vidal-Gomel, Le Bellu, 2020): 
"The thing that I did unconsciously because I am used to doing it, is to take enough distance from the van in front of us before activating, otherwise you start your regulation by braking and it is not very pleasant ». Study 1, subject 2.

This "Results" section aims at highlighting the differences with "traditional" driving through $\mathrm{AD}$ experienced situations. The results represent the current state of the art on the developments of AV prototype tested, so they will probably evolve. Indeed, the classification of situations that we propose constitutes an entry for: (1) taking them into account by the designers to improve systems, and (2) their integration into learning tools for future AV drivers in order to facilitate appropriation of these new systems. Our research mainly focuses on this second point.

\section{Discussion}

\subsection{Traces (among professionals) and clues (among novices) of a potential instrumental genesis of the AV}

These results show that the introduction of an $\mathrm{AD}$ mode leads to a modification of the relations and mediations at stake in driving situations that already exist in "traditional" driving. The driver will have to adapt by learning to manage them differently (classes B and C). In addition, completely new driving situations, including their own relations and mediations, are emerging. The driver will have to learn to manage them (class A). The observation of drivers' adaptations in these new situations can translate potential schemes transformations. Thus, when a driver favors the use of the accelerator pedal each time he deactivates and says during auto-confrontation interview: "Often it is the accelerator because I used ... there is also the habit that I have with the cruise control. " (study 2, subject 4); we can think that he assimilated this scheme of use from the cruise control for the deactivation of AD. On the other hand, regarding the activation of $\mathrm{AD}$, we observe failures at the start of the first driving session in more than $60 \%$ of novice drivers. However they manage to adapt before the end of this session: "The first time, indeed, I didn't even succeed on the first try [...] It was not so easy for me at first to know when it was the right time or not. At the end I was a little more comfortable » (study 2, subject 10). In this specific case, we believe that error plays a fundamental role in learning (Dehaene, 2018) and allows these drivers to accommodate some of their action schemes in order to achieve their goal (in this case, the goal is to activate AD). Finally, we observe gestures and verbalizations that may suggest an active inhibition (Pascual-Leone, 1987; Houdé, 2000) of certain automatisms (or schemes) of "traditional" driving. For example, the inhibition of the reflex to press on the brake pedal when there is a cut-in, or the inhibition of the action on the steering wheel to shift into the lane when overtaking a truck (Cusanno, Vidal-Gomel \& Le Bellu, 2020). These scheme transformations (or their absence in certain subjects) are observable in both populations studied. We hypothesize that they are the markers of the subjects' instrumentation processes (Rabardel, 1995). 
We also observe changes in the nature of certain mediations, moving from pragmatic (preparing an action on driving) to epistemic (knowledge of driving management by the AV), reflecting the attribution of new functions to artefacts. This allocation of new functions concerns the use of the AV interfaces, no longer to manage class $\mathrm{B}$ situations (driving situations managed by AD) but to control their smooth running and the AV actions. Other mediations keep the same nature but are given new functions, such as the use of controls (steering wheel and pedals) to deactivate AD. We believe that these modifications, observed in both populations, are markers of an AV instrumentalization process (Rabardel, 1995).

Thus, we were able to recompose, on one hand a subject (driver) instrumentation process, and on the other hand an artefact (AV) instrumentalization process which are, according to Rabardel, the instrumental genesis constituents.

Finally, the object of professional drivers' activity differs from novice drivers. Their in-depth knowledge of the capabilities and limitations of $\mathrm{AD}$, acquired through their empirical experience, enabled them to develop a representation of the system that provides an appropriate trust in AV (Lee \& See, 2004). They can recognize sensitive situations and anticipate the AV behavior. This ability allows them to establish a reliable and quick diagnosis, and take appropriate decisions in dynamic situations (according to the model of Hoc \& Amalberti, 1994; Hoc \& Amalberti, 2007). Raising the awareness of future AV drivers to these situations via an appropriate educational content could be a lead to follow to help them (Le Bellu, in prep.). This educational content could be supplemented with advices and recommendations issued by professional AV drivers. Their "professional" point of view (Goodwin, 1994) allows them to analyze their own activity and be aware of their schemes' adaptations, by externalizing this meta-knowledge, which could be the subject of advices.

\subsection{Limits}

The methodological limitations of the first study with professional drivers are discussed in detail in Cusanno, Vidal-Gomel \& Le Bellu (2020). Regarding the second study, note two main limitations: 1) the vehicle used is an unfinished AV prototype (for example, failure during activation can be partly explained by a complex activation procedure inherent in the prototype), 2) the safe presence of the safety driver in the vehicle during the driving session (more than half of the participants report having explored the use of the AV more than if they had been alone).

\section{Conclusion}

The results of these two studies allow us to attempt to reconstruct the instrumental genesis of a driver during the appropriation of an AV, thanks to the analysis of the new relations and mediations at stake in sensitive driving situations specific to AD. The first study allowed us to approach different integration levels of the new schemes developed by professional drivers and to collect advices and recommendations for getting started with the AV. The results of the second study are consistent with those of the first study concerning the sensitive situations identified and the 
potential schemes transformations associated with these situations. They also make it possible to consider the importance of trust for the appropriation of the AV by drivers new to this technology. Session 3 results analysis will confirm and complete these results after three sessions in AV. Note that these two studies report the current state of the art in SAE level 3-4 AV prototype design, and the results presented in this paper will be taken into account to improve future AD systems.

Moreover, we can now think about the design of a learning tool for AV appropriation by considering these results which guide the choice of educational content to be integrated. This content should be scalable to adapt to changes in future AD systems. For example, it would be interesting to try to facilitate the drivers' schemes transformations by presenting the sensitive $\mathrm{AD}$ situations upstream. Mayen and Gagneur (2017) talk about pedagogy of situations. This could potentially relieve the driver cognitively in real driving situations, in particular by preparing the inhibition of certain existing schemes (Houdé, 2000). More broadly, the idea of orchestrating a system of instruments, integrating devices offered beyond onboard artefacts, for learning (Trouche, 2003) could make it possible to play on the redundancy and complementarity of shared knowledge. The advices and recommendations gathered in the first study could be included alongside more general information about AV and AD. Thus, the onboard learning tool that we have to design should be thought as part of the way in which the orchestration is designed.

\section{References}

Apostolidis, T. (2003). Représentations sociales et triangulation : enjeux théoricométhodologiques. Méthodes d'étude des représentations sociales, 13-35.

Clot, Y., \& Leplat, J. (2005). La méthode clinique en ergonomie et en psychologie du travail. Le travail humain, 68(4), 289-316.

Cusanno, H., Vidal-Gomel, C. \& Le Bellu, S. (2019). Comment guider les genèses instrumentales pour la prise en main du véhicule autonome ? In Actes du $5^{\text {ème }}$ Colloque International de Didactiques Professionnelle, Former \& développer l'intelligence professionnelle (pp. 145-158). Montréal, 23, 24 et 25 oct 2019.

Cusanno, H., Vidal-Gomel, C. \& Le Bellu, S. (2020). Comment guider les genèses instrumentales pour la prise en main d'un véhicule automatisé ? In Actes du 55ème Congrès de la SELF, L'activité et ses frontières. Penser et agir sur les transformations de nos sociétés (pp. 336-341). Paris, 11, 12 et 13 jan 2021.

Dehaene, S. (2018). Apprendre! : les talents du cerveau, le défi des machines (Learning ! : The talents of the brain, the challenge of machines). Odile Jacob, 293-321.

Goodwin, C. (1994), Professional Vision. American Anthropologist, 96: 606-633. https://doi.org/10.1525/aa.1994.96.3.02a00100

Hoc, J. M., \& Amalberti, R. (1994). Diagnostic et prise de décision dans les situations dynamiques. Psychologie française, 39(2), 177-192.

Hoc, J. M., \& Amalberti, R. (2007). Cognitive Control Dynamics for Reaching a Satisficing Performance in Complex Dynamic Situations. Journal of Cognitive Engineering and Decision Making, 1(1), 22-55. https://doi.org/10.1177/155534340700100102 
Houdé, O. (2000). Inhibition and cognitive development: Object, number, categorization, and reasoning. Cognitive development, 15(1), 63-73.

Kyriakidis, M., de Winter, J. C., Stanton, N., Bellet, T., van Arem, B., Brookhuis, K., ... \& Happee, R. (2019). A human factors perspective on automated driving. Theoretical Issues in Ergonomics Science, 20(3), 223-249.

Le Bellu, S. (in prep.). Are we ready for driving an automated vehicle? Need to support the familiarization of future users.

Lee, J. D., \& See, K. A. (2004). Trust in automation: Designing for appropriate reliance. Human factors, 46(1), 50-80.

Lefebvre, C. (2001). Vers une formation à la conduite automobile intégrant des connaissances conceptuelles et des métaconnaissances. Recherche-transports-sécurité, 70, 16-40. https://doi.org/10.1016/S0761-8980(01)90225-0

Mayen, P., \& Gagneur, C. A. (2017). Le potentiel d'apprentissage des situations : une perspective pour la conception de formations en situations de travail. Recherches en éducation, 28, 70-83.

Mollo, V., \& Falzon, P. (2004). Auto-and allo-confrontation as tools for reflective activities. Applied ergonomics, 35(6), 531-540.

Mundutéguy, C., \& Darses, F. (2007). Perception and Anticipation of Others' Behavior in a Simulated Car Driving Situation. Le travail humain, 70(1), 1-32.

Olsen, W. (2004). Triangulation in social research: qualitative and quantitative methods can really be mixed. Developments in sociology, 20, 103-118.

Pascual-Leone, J. (1987). Organismic processes for neo-Piagetian theories: A dialectical causal account of cognitive development. International Journal of Psychology, 22(5-6), 531-570.

Rabardel, P. (1995). Les hommes et les technologies ; approche cognitive des instruments contemporains. Armand Colin.

Society of Automotive Engineers (2018). Taxonomy and Definitions for Terms Related to Driving Automation Systems for On-Road Motor Vehicles. www.sae.org/standards/content/j3016_201806

Trouche, L. (2003). Construction et conduite des instruments dans les apprentissages mathématiques : nécessité des orchestrations. hal-00190091.

Verillon, P., \& Rabardel, P. (1995). Cognition and artifacts: A contribution to the study of though in relation to instrumented activity. European journal of psychology of education, 77-101.

Vidal-Gomel, C., Delgoulet, C., \& Geoffroy, C. (2014). Compétences collectives et formation à la conduite d'engins de secours dans un contexte de spécialisation des sapeurs-pompiers en France. Perspectives Interdisciplinaires sur le Travail et la Santé, (16-4). 